\title{
IMPACT OF GOAL ORIENTATION, PERSONALITY TYPES AND CAMPUS CLIMATE AT UIN SYARIF HIDAYATULLAH JAKARTA NURSING STUDENT'S WORK READINESS
}

\author{
Citra Kemilau Ramadhania \\ citrakemilau@gmail.com
}

Anggota HIMPSI Provinsi Tangerang Selatan

\author{
Mulia Sari Dewi \\ mulia.sari@uinjkt.ac.id \\ Fakultas Psikologi UIN Syarif \\ Hidayatullah Jakarta
}

\begin{abstract}
The rapid development of science and technology resulted in increasingly tight competition on obtaining work. Moreover, with the implementation of the trade zone of the Asean Economic Community (AEC) currentlyits the realization of the Asia free market. There are eight professions involved in MEA competition, among which the the field of nursing, so the work readiness become important that a student should have when facing the world of work. This study was conducted to determine the influence of significants goal orientation, personality type, and campus climate on work readiness. Subjects in this study is 5 to 9 semester student of nursing and 1 and 3 semester of UIN Syarif Hidayatullah nurses profession student amounted to 151 are taken by purposive sampling technique. The results show that there an influence of goal orientation, personality type, and campus climate on work readiness is significant with the proportion of the variance is $63.6 \%$. The hypothesis minor test show that emotionality, extraversion, conscientiousness, and teaching learning have a significant influence on work readiness. While learning goals, performance goals, honesty-humility, agreeableness, openness to experience, safety, interpersonal relations and the institutional environment have no significant effect. Suggestions for subsequent research in order to use other variables in order to enrich this study.
\end{abstract}

Keyword: Work readiness, goal orientation, personality types and campus climate.

\begin{abstract}
Abstrak
Perkembangan ilmu pengetahuan dan teknologi semakin pesat mengakibatkan persaingan semakin ketat dalam memperoleh pekerjaan. Terlebih dengan diberlakukannya zona perdangan Masyarakat Ekonomi Asean (MEA) saat ini yang merupakan realisasi pasar bebas Asean. Terdapat delapan bidang profesi yang terlibat dalam persaingan MEA, diantaranya yaitu bidang keperawatan, sehingga dalam menyikapi hal ini kesiapan kerja menjadi hal penting yang harus dimiliki oleh mahasiswa, karena akan menghadapi dunia kerja. Penelitian ini dilakukan untuk mengetahui signifikinasi goal orientation, tipe kepribadian dan iklim kampus terhadap kesiapan kerja. Subjek dalam penelitian ini mahasiswa ilmu keperawatan UIN Syarif Hidayatullah Jakarta semester 5 sampai 9 dan mahasiswa profesi ners semester 1 dan 3 berjumlah 151 yang diambil dengan teknik purposive sampling. Hasil penelitian menunjukkan bahwa, ada pengaruh yang siginifikan goal orientation, tipe kepribadian dan iklim kampus terhadap kesiapan kerja. Uji hipotesis minor menunjukkan bahwa emotionality, extraversion, conscientiousness, dan pengajaran pembelajaran memiliki pengaruh yang signifikan terhadap kesiapan kerja. Sementara learning goal, performance goal, honesty-humility, agreeableness, openness to experience, keselamatan, hubungan interpersonal dan lingkungan institusional tidak berpengaruh signifikan. Saran bagi penelitian berikutnya agar menggunakan variabel lain supaya memperkaya kajian ini, seperti variabel kecerdasan emosinal, pengalaman kerja, dan self efficacy.
\end{abstract}

Kata kunci: Kesiapan Kerja, Goal Orientation, Tipe Kepribadian, Iklim Kampus 


\section{PENDAHULUAN}

Semakin pesatnya perkembangan ilmu pengetahuan dan teknologi mengakibatkan adanya perubahan dan tuntutan baru dalam masyarakat, diantaranya dalam kualifikasi permintaan perusahaan terhadap tenaga kerja yang semakin tinggi, sehingga persaingan menjadi ketat dalam memperoleh pekerjaan yang menyebabkan jumlah pengangguran di Indonesiasemakin meningkat. Sedangkan berdasarkan Badan Pusat Statistiktercatat pada Februari 2016 tingkat pengangguran terbuka dari lulusan perguruan tinggi mencapai 8,39\% atau setara dengan 144.500 orang.

Kellermann dan Sagmeister (2010) menyatakan bahwa pengangguran terus bertambah setiap tahun, khususnya pengangguran dari lulusan perguruan tinggi. Terlebih dengan diberlakukannya zona perdagangan Masyarakat Ekonomi ASEAN (MEA) saat ini yang merupakan realisasi pasar bebasASEAN. Dimulainya MEA tentu akan memberikan dampak positif sekaligus dampak negatif. Dampak positifnya adalah pemasaran barang, jasa dan tenaga kerja dari Indonesia dapat memperluas jangkauan ke negara ASEAN, sehingga ketenagakerjaan Indonesia dapat mencari pekerjaan di luar negeri dengan aturan yang lebih mudah, namun dampak negatifnya adalah persaingan ketenaga kerjaan yang semakin ketat, dikarenakan tenaga kerja asing akan masuk ke Indonesia (Ruhimat, 2011). Ketua Umum Asosiasi Pengusaha Indonesia, Sofjan Wanandi (2015) menilai Indonesia saat ini memiliki tiga persoalan seputar ketenagakerjaan, terutama dalam menghadapi MEA, diantaranya yaitu kesempatan kerja yang terbatas, rendahnya kualitas angkatan kerja, dan tingginya tingkat pengangguran.

Berdasarkan Mutual Recognition Arrangements (MRA) telah ditetapkan delapan profesi yang akan terlibat dalam persaingan pasar bebas yang tertuang dalam ASEAN, diantaranya adalah bidang akuntansi, teknik, tenaga survei, arsitektur, keperawatan, kesehatan, perawatan gigi dan pariwisata (Wilda $\mathrm{R}$, 2014). Berdasarkan data dari Kementerian Kesehatan RI (2014), permintaan tenaga kesehatan meningkat pesat dan perawat menempati porsi kebutuhan terbesar dengan tingkat permintaan yang terus melonjak baik dari Indonesia maupun luar negeri. Namun keperawatan di Indonesia masih cukup tertinggal dibanding negara ASEAN, seperti kelemahan dalam bahasa asing.

Pendidikan merupakan salah satu sarana untuk meningkatkan kualias SDM, sehingga tuntutan terhadap dunia pendidikan sangat tinggi. Menurut Ferns (2012) bahwa perusahaan ingin mendapatkan lulusan yang memilikikesiapan kerja, yaitu memiliki kapasitas intelektual dan juga dilengkapi dengan keahlian kerja, sesuai denganpenelitian yang dilakukan oleh Caballero et.al. (2010) dalam jurnal yang berjudul "Work readiness in graduate recruitment and selection: A review of current assessment methods"diungkapkan bahwa perusahaan menempatkan peningkatan nilai pada lulusan yang siap kerja, karena lulusan yang memiliki kesiapan kerja dipandang sebagai potensi dalam kemajuan karir.

Kesiapan kerja disebut juga dengan soft skill yang merupakan seperangkat keahlian dan perilaku yang diperlukan individu pada setiap pekerjaan, yang meliputi keterampilan transisi, komunikasi, kualitas diri, dan keterampilan terhadap teknologi (Wagner, J. O. 2006). Selain itu, Wall, B. (2007) juga 
berpendapat bahwa sikap kesiapan kerja sangat mempengaruhi seseorang untuk mendapatkan pekerjaan. Sedangkan menurut Pool dan Sewell (2007) untuk memiliki kesiapan kerja yang tinggi diperlukan beberapa hal yaitu keahlian sesuai dengan bidangnya, wawasan yang luas, pemahaman dalam berpikir, dan kepribadian baik yang membuat seseorang dapat memilih dan merasa nyaman dengan pekerjaannya sehingga meraih sukses. Berdasarkan penelitian sebelumnya, beberapa variabel ditemukan memiliki pengaruh yang signifikan terhadap kesiapan kerja yang terdiri dari faktor internal dan faktor eksternal. Faktor internal meliputi self efficacy, kecerdasan emosional, dan pengalaman kerja, (Solberg, et.al. 1994; Carol, A. 2014; Pool \& Sewell, 2007;), sedangkan faktor eksternal adalah faktor sosial yang meliputi bimbingan dari orang tua, keadaan teman sebaya, dan keadaan masyarakat sekitar (Ketut, 1993).

Dari penelitian sebelumnya menunjukkan bahwa faktor internal yang diprediksi lebih banyak berpengaruh terhadap kesiapan kerja. Ada pula faktor internal lainnya yaitu goal orientation. Berdasarkan penelitian sebelumnya yang dilakukan oleh Staci, C. (2007) mengungkapkan bahwa goal orientation memberikan dampak positif terhadap program kesiapan kerja. Goal orientation dianggap sebagai suatu konstruk motivasi penting yang terkait dengan perilaku dan hasil kinerja. Sesuai dengan gagasan yang dikemukakan oleh Rich A. Radcliffe \& Beth (2013) bahwa untuk membangun kesiapan kerja perlu meningkatkan beberapa aspek, diantaranya adalanya goal orientation.

Goal orientation merupakan alasan individuberperilaku tertentu untuk mencapai suatu tujuan yang terdiri dari learning goal dan performance goal. Individu dengan kecenderungan learning goal akan melihat situasi sebagai untuk mengembangkan keterampilannya. Dengan demikian, apabila individu memiliki learning goal maka akan siap dalam memasuki dunia kerja, karena lingkungan kerja merupakan situasi baru yang menantang. Selain itu individu dengan kecenderungan performance goal akan menghindari kegiatan yang menantang karena menghindari kegagalan dan berusaha menunjukkan kompetensi terbaik yang dimiliki agar memperoleh penilaian positif dari orang lainyang akan meningkatkan kesiapan individu dalam memasuki dunia kerja.

Faktor internal selanjutnya yang diprediksi mempengaruhi kesiapan kerja adalah tipe kepribadian. Berdasarkan hasil penelitian yang dilakukan oleh Landrum, et.al. (2010) mengatakan bahwa mahasiswa dapat meningkatkan keterampilan dengan mengembangkan tipe kepribadiannya yang akan berkontribusi terhadap kesiapan untuk melakukan suatu pekerjaan. Sesuai dengan pendapat Archer dan Davison (2008) kepribadian merupakan salah satu keterampilan dan kemampuan terpenting dalam merekrut seorang fresh graduate. Archer dan Davison (2008) juga menegaskan bahwa sebagian besar perusahaan lebihmementingkan kepribadian daripada kualifikasi sebuah gelar.

Penelitian sebelumnya juga dilakukan oleh Paul dan Philip (2014) yang mengatakan bahwa atribut conscientiousness dan agreeableness sangat penting terhadap kesiapan seseorang dalam memasuki dunia kerja. Individu dengan sikap agreeableness yang tinggi akan siap dalam memasuki dunia kerja, dikarenakan memiliki sikap fleksibel dimana akan terbuka dalam menghadapi kritik, memiliki sikap toleran dimana akan menghargai perbedaann dan pendapat orang lain, dan 
memiliki sikap sabar jika menghadapi sebuah tekanan. Selanjutnya, individu dengan sikap conscientiousness tinggi dikatakan akan siap memasuku dunia kerja karena mereka termasuk seorang yang perfeksionis maka akan berusaha menyelesaikan suatu tugas dengan hati-hati dan terorganisir, selain itu juga mereka termasuk seorang yang rajin.

Selain faktor internal, ada pula faktor eksternal yang diprediksi berpengaruh terhadap kesiapan kerja yaitu iklim kampus. Sebenarnya belum ada penelitian yang mengatakan bahwa iklim kampus berpengaruh secara langsung terhadap kesiapan kerja, namun iklim kampus memiliki peran dalam proses pembelajaran. Seperti yang diungkapkan oleh Haahr, et.al.(2005) bahwa kualitas iklim kampus berpengaruh terhadap hasil akademik mahasiswa. Selain itu, menurut Thapa, et.al. (2012) iklim kampus yang positif juga akan memiliki pengaruh yang kuat terhadap motivasi belajar mahasiswa. Sesuai yang diungkapkan oleh Rankin (2014) iklim kampus dapat mempengaruhi keberhasilan akademis mahasiswa, dimana iklim kampus dapat mempengaruhi hasil belajar.

UIN Syarif Hidayatullah Jakarta merupakan salah satu kampus yang memiliki visi dapat bersaing tinggi dan terdepan dalam mengembangkan dan mengintegrasikan aspek keislaman, keilmuan, kemanusiaan, dan keindonesiaan. Terlihat dari visi kampus UIN Syarif Hidayatullah Jakarta itu sendiri yang berarti kampus dapat menyelenggarakan pendidikan bermutu dan berkompeten yang dapat bersaing secara global, sehingga mahasiswanya lulus dengan harapan sudah memiliki kesiapan kerja, sekaligus memiliki kompentensi sesuai dengan bidang keahliannya untuk mulai menghadapi dunia kerja.

Berdasarkan fenomena dan latar belakang masalah yang dikemukakan, maka penulis tertarik untuk meneliti mahasiswa prodi ilmu keperawatan di UIN Syarif Hidayatullah Jakarta. Alasan memilih untuk meneliti prodi ilmu keperawatan seperti yang sudah dijelaskan sebelumnya karena profesi keperawatan termasuk salah satu dari delapan profesi yang bersaing dalam MEA, maka penulis akan mengambil judul "Pengaruh goal orientation, tipe kepribadian dan iklim kampus terhadap kesiapan kerja mahasiswa ilmu keperawatan UIN Syarif Hidayatullah Jakarta".

\section{KAJIAN TEORI}

\section{Kesiapan Kerja}

Definisi kesiapan kerja dari Cabballero, et.al. (2011) yaitu sikap, keterampilan dan pengetahuan yang dimiliki lulusan, sehingga memiliki kesiapan dalam bekerja atau siap untuk sukses dalam lingkungan kerja.

\section{Goal Orientation}

Berdasarkan teori goal orientation yang dikemukakan, maka disimpulkan bahwa goal orientation dalam penelitian ini adalah respon individu dalam menafsirkan sebuah prestasi dan menanggapi umpan balik dari kinerja yang dilakukan. (Button, et.al. 1996).

\section{Tipe Kepribadian}

Dalam penelitian ini menggunakan tipe kepribadian HEXACO dari Ashton dan Lee (2007) untuk memahami kepribadian para mahasiswa prodi ilmu 
keperawatan di UIN Syarif Hidayatullah Jakarta dalam kesiapan memasuki dunia kerja. Dikarenakan tipe kepribadian HEXACO merupakan pengembangan dari teori Big Five.

\section{Iklim Kampus}

Berdasarkan teori iklim kampus yang dikemukakan, maka penulis menyimpulkan iklim kampus yang dikemukakan oleh Cohen (2010) yang mengemukakan bahwa iklim kampus adalah persepesi masyarakat di sekitar kampus mengenai keadaan kampus yang mencerminkan norma-norma, nilai-nilai, hubungan interpersonal, belajar mengajar, dan struktur organisasi.

\section{METODE PENELITIAN}

\section{Populasi, sampel dan teknik pengambilan sampel}

Populasi dalam penelitian ini adalah mahasiswa yang tercatat aktif kuliah pada prodi ilmu keperawatan UIN Syarif Hidayatullah Jakarta dari semester 5 sampai semester 9 dan profesi ners semester 1 dan semester3. Jumlah sampel dalam penelitian ini sebanyak 151 orang. Teknik pengambilan sampel dalam penelitian ini dilakukan dengan cara non-probability sampling, yaitu menggunakan teknik purposive sampling. Penulis melakukan penelitian secara langsung dengan memberikan kuisioner kepada mahasiswa prodil ilmu keperawatan UIN Syarif Hidayatullah Jakarta.

\section{Instrumen penelitian}

Terdapat empat alat ukur yang digunakan peneliti dalam penelitian ini, yaitu:

1. The Work Readiness Scale (WRS)

Alat ukur yang dikembangkan oleh Caballero, et.al (2011) mengenai kesiapan kerja memiliki empat dimensi yang merupakan suatu kesatuan yang tak terpisahkan yaitu karakteristik personal, kecerdasarn organisasi, kecerdasan sosial, dan kompetensi kerja yang terdiri dari 23 item.

\section{Instrumen goal orientation}

Untuk mengukur goal orientation dalam penelitian ini penulis mengadaptasi alat ukur yang dikembangkan oleh Button, et.al (1996). Skala ini terdiri dari 16 item yang mencakup dua dimensi yaitu learning goal dan performance goal.

\section{Tipe kepribadian HEXACO}

Untuk mengukur tipe kepribadian terdapat alat ukur baku yang sudah tersedia yang dibuat oleh Ashton dan Lee (2009) yaitu HEXACO-PR. Alat ukur ini mengukur enam dimensi tipe kepribadian HEXACO, yaitu honesty-humility, emotionality, extraversion, agreeableness, conscientiousness, dan openness to experience. HEXACO-PR terdiri dari 60 item, namun penulis memutuskn untuk memodifikasi dengan mengurangi jumlah item menjadi 24 item.

\section{Iklim kampus}

Alat ukur yang digunakan dalam penelitian ini mengadaptasi alat ukur yang dikembangkan oleh Cohen (2008) yaitu CSCI (comprehensive school climate inventory) yang berjumlah 73 item pernyataan, namun penulis memutuskan untuk memodifikasi dengan mengurangi jumlah item, sehingga menjadi 21 item. 


\section{HASIL PENELITIAN}

Besaran Muatan Independent Variable terhadap Dependent Variable

Total sampel pada penelitian ini adalah sebanyak 151 mahasiwa ilmu keperawatan UIN Syarif Hidayatullah Jakarta. Selanjutnya akan dijelaskan gambaran subjek lebih rinci pada tabel 4.1 berikut :

\section{Tabel 4.1}

Subjek Penelitian

\begin{tabular}{lcc}
\hline \multicolumn{1}{c}{ Deskripsi } & Jumlah & Presentase (\%) \\
\hline Jenis Kelamin & & \\
Perempuan & 139 & $92 \%$ \\
Laki-Laki & 12 & $8 \%$ \\
Tingkat Semester & & \\
5 & 31 & $20 \%$ \\
7 & 46 & $30 \%$ \\
9 & 4 & $3 \%$ \\
Profesi Ners 1 & 36 & $24 \%$ \\
Profesi Ners 3 & 34 & $23 \%$ \\
Total & 151 & $100 \%$ \\
\hline
\end{tabular}

\section{Hasil uji hipotesis}

\section{Tabel 4.2}

Analisis Regresi

\begin{tabular}{|c|c|c|c|c|c|c|}
\hline Model & $\overline{\mathrm{R}}$ & \multicolumn{2}{|l|}{ R Square } & $\begin{array}{l}\text { Adjusted R } \\
\text { Square }\end{array}$ & \multicolumn{2}{|c|}{$\begin{array}{l}\text { Std. Error of the } \\
\text { Estimate }\end{array}$} \\
\hline 1 & $.798 \mathrm{a}$ & \multicolumn{2}{|l|}{.636} & .604 & \multicolumn{2}{|c|}{590.276} \\
\hline \multicolumn{7}{|c|}{$\begin{array}{l}\text { Dari tabel } 4.2 \text { dapat dilihat bahwa perolehan } \mathrm{R} \text { square sebesar } 0,636 \text { atau } 63,6 \% \\
\text { artinya proporsi varians dari kesiapan kerja dijelaskan oleh learning goal, } \\
\text { performance goal, honesty-humility, emotionality, extraversion, agreeableness } \\
\text { conscientiousness, openness to experience, keselamatan, pengajaran dan } \\
\text { pembelajaran, hubungan interpersonal, dan lingkungan institutiona sebaga } \\
\text { independent variable adalah sebesar } 63,6 \% \text { sedangkan } 36,4 \% \text { sisanya dipengaruh } \\
\text { oleh variabel lain diluar penelitian ini }\end{array}$} \\
\hline \multicolumn{7}{|l|}{$\begin{array}{l}\text { Tabel } 4.3 \\
\text { Anova }\end{array}$} \\
\hline Model & & $\begin{array}{l}\text { Sum of } \\
\text { Squares }\end{array}$ & Df & Mean Square & $\mathrm{F}$ & Sig \\
\hline $\begin{array}{l}\text { 1Regression } \\
\text { Residual }\end{array}$ & & $\begin{array}{l}8.403 .823 \\
4.808 .275\end{array}$ & $\begin{array}{c}12 \\
138\end{array}$ & $\begin{array}{r}700.319 \\
34.843\end{array}$ & 20.100 & $.000^{\mathrm{b}}$ \\
\hline Total & & 13.212 .098 & 150 & & & \\
\hline
\end{tabular}


Jika melihat kolom sig diketahui bahwa sig $(<0,05)$ maka hipotesis nihil yang menyatakan tidak ada pengaruh yang signifikan dari learning goal, performance goal, honesty-humility, emotionality, extraversion, agreeableness,conscientiousness, openness to experience, keselamatan, pengajaran dan pembalajaran, hubungan interpersonal, dan lingkungan instutisonal sebagai independent variable terhadap kesiapan kerja tidak diterima.

\section{Koefesien Regresi}

Berdasarkan tabel 4.4 dapat dipaparkan persamaan regresi sebagai berikut:

Kesiapan kerja $=8.734+0,124$ learning goal- 0,013 performance goal $+0,024$ honesty-humility- 0,207 emotionality* $+0,238$ extraversion*0,104 agreeableness +0.192 conscientiousness $*+0,186$ openness to experience $+0,042$ keselamatan $+0,246$ pengajaran dan pembeajaran* - 0,095 hubungan interpersonal $+0,102$ lingkungan institusional.

Keterangan: signifikan $\left(^{*}\right)$

Tabel 4.4

Koefisien Regresi

\begin{tabular}{|c|c|c|c|c|c|}
\hline \multirow[b]{2}{*}{ Model } & \multicolumn{2}{|c|}{$\begin{array}{l}\text { Unstandardized } \\
\text { Coefficients }\end{array}$} & \multicolumn{3}{|c|}{$\begin{array}{l}\text { Standardized } \\
\text { Coefficients }\end{array}$} \\
\hline & B & $\begin{array}{l}\text { Std. } \\
\text { Error }\end{array}$ & Beta & $\mathrm{T}$ & Sig. \\
\hline 1 (Constant) & 8.734 & 6.624 & & 1.319 & .189 \\
\hline Learning Goal & .124 & .074 & .128 & 1.681 & .095 \\
\hline Performance Goal & -.013 & .060 & -.012 & -.209 & .835 \\
\hline Honesty-Humility & .024 & .066 & .025 & .360 & .719 \\
\hline Emotionality & -.207 & .072 & -.172 & -2.893 & .004 \\
\hline Extraversion & .238 & .090 & .230 & 2.565 & .011 \\
\hline Agreeableness & -.104 & .096 & -.013 & -.158 & .875 \\
\hline Conscientiousness & .192 & .103 & .180 & 1.996 & .048 \\
\hline $\begin{array}{l}\text { Openness to } \\
\text { Experience }\end{array}$ & .186 & .085 & .157 & 1.809 & .073 \\
\hline Keselamatan & .042 & .081 & .040 & .509 & .617 \\
\hline $\begin{array}{l}\text { Pengajaran dan } \\
\text { Pembelajaran }\end{array}$ & .246 & .081 & .246 & 3.3036 & .003 \\
\hline $\begin{array}{l}\text { Hubungan } \\
\text { Interpersonal }\end{array}$ & -.095 & .069 & -.085 & -1.170 & .244 \\
\hline $\begin{array}{l}\text { Lingkungan } \\
\text { Institusionl }\end{array}$ & .102 & .069 & .093 & 1.471 & .144 \\
\hline
\end{tabular}




\section{Proporsi varians}

Untuk proporsi varians dari masing-masing Independent variable terhadap kesiapan kerja terdapat empat variabel yang secara signifikan memberikan sumbangan terhadap varians keterikatan karyawan pada perusahaan, yaitu:

1. Variabel emotionality memberikan sumbangan sebesar $5,8 \%$ terhadap varians kesiapan kerja.

2. Variabelextraversionmemberikan sumbangan sebesar $17,4 \%$ terhadap varians kesiapan kerja.

3. Variabel conscientiousness memberikan sumbangan sebesar 1,8\% terhadap varians kesiapan kerja.

4. Variabel pengajaran dan pembelajaran memberikan sumbangan sebesar $0,23 \%$ terhadap varians kesiapan kerja.

\section{KESIMPULAN DAN SARAN}

\section{Kesimpulan}

Berdasarkan hasil analisis, kesimpulan dari penelitian ini, adalah secara keseluruhan terdapat pengaruh yang signifikan variabel kesiapan kerja dipengaruhi oleh goal orientation, tipe kepribadian dan iklim kampus sebesar $63,6 \%$, sedangkan $36,4 \%$ sisanya dapat dijelaskan dengan variabel lain diluar variabel yang digunakan dalam penelitian ini. Hal ini menunjukan bahwa hipotesis mayor yang menyatakan bahwa ada pengaruh yang signifikan antaragoal orientation, tipe kepribadian dan iklim kampus terhadap kesiapan kerja diterima. Berdasarkan hasil penelitian dapat dilihat melalui koefisien regresi bahwa hanya terdapat empat dari dua belas variabel yang berpengaruh signifikan terhadap kesiapan kerja.

\section{Diskusi}

Berdasarkan hasil penelitian dan pengujian hipotesis, didapatkan bahwa emotionality dari variabel tipe kepribadian memiliki pengaruh yang signifikan terhadap kesiapan kerja pada mahasiswa ilmu keperawatan di UIN Syarif Hidayatullah Jakarta dengan arah negatif. Dari arah hubungan dapat diartikan bahwa semakin tinggi tingkat emotionality seseorang akan cenderung sering mengalami rasa takut, khawatir dalam berbagai hal, lebih membutuhkan dukungan secara emosional dari orang lain dan lebih sentimental, begitupun sebaliknya. Dengan demikian, dapat diartikan bahwa tingkat emotionality mahasiswa ilmu keperawatan UIN Syarif Hidayatullah Jakarta rendah yang berarti cenderung memiliki emosi yang stabil dan tenang. Selanjutnya, extraversion dari variabel tipe kepribadian memiliki pengaruh yang signifikan dengan arah hubungan positif, sehingga semakin tinggi tingkat extraversion mahasiswa ilmu keperawatan maka kesiapan kerjanya akan semakin tinggi. Conscientiousness dari variabel tipe kepribadian juga yang memberikan pengaruh signifikan dengan arah hubungan yang positif terhadap kesiapan kerja. Dari arah hubungan tersebut dapat diartikan bahwa semakin tinggi tingkat conscientiousness mahasiswa ilmu keperawatan maka semakin siap dalam memasuki dunia kerja. Berdasarkan hasil penelitian yang dilakukan terdapat juga delapan independent variable yang tidak terbukti memiliki pengaruh terhadap kesiapan kerja mahasiswa ilmu keperawatan 
UIN Syarif Hidayatullah Jakarta. Adapun variabel tersebut adalah learning goal, performance goal, honesty-humility, agreeableness, openness to experience, keselamatan, hubungan interpersonal dan lingkungan institusional.

\section{Saran}

\section{Saran Teoritis}

1. Pada penelitian selanjutnya, disarankan untuk mempertimbangkan dan menggunakan variabel lain seperti variabel kecerdasan emosional, pengalaman kerja dan self efficacy. Selain itu, terkait variabel pengajaran dan pembelajaran memberikan pengaruh signifikan terhadap kesiapan kerja, sehingga disarannya dalam penelitian selanjutnya untuk meneliti tipe kepribadian dosen.

2. Pada penelitian selanjutnya, penulis menyarankan agar memperbanyak jumlah sampel penulisan serta memperluas wilayah sampel penelitian, seperti mengambil sampel dari beberapa kampus sehingga dapat terlihat kesiapan kerja pada mahasiswa ilmu keperawatan.

\section{Saran Praktis}

1. Penulis menyarankan supaya mahasiswa menjaga emosinya tetap stabil, karena dalam dunia kerja dibutuhkan seseorang yang tetap tenang dalam sebuah tekanan. Profesi perawat dalam menangani pasiennya dibutuhkan seseorang yang memiliki kesabaran lebih dan penuh cinta.

2. Untuk mahasiswa mengikuti organisasi baik di dalam maupun di luar kampus, agar mudah dalam beradaptasi di lingkungan baru. Selain itu mengikuti berbagai kegiatan sosial, untuk melatih jiwa sosial, karena di dalam dunia kerja dibutuhkan seseorang yang mudah bersosialisasi, terutama pada profesi perawat yang harus ramah dalam menangani pasiennya dan juga memiliki kepedulian yang lebih.

3. Untuk itu, penulis menyarankan mahasiswa lebih terorganisir, seperti dapat mengatur waktu dengan baik yaitu menyelesaikan tugas sebelum deadline, selain itu mahasiswa lebih hati-hati dalam melakukan sesuatu, karena profesi perawat indentik dengan kehati-hatian dalam menangani pasien.

4. Pihak kampus disarankan untuk lebih sering mengadakan pelatihan yang terjun langsung ke lapangan, seminar mengenai dunia kerja terkait MEA. Selain itu mengadakan kelas bilingual untuk meningkatkan kemampuan bahasa inggris mahasiswa. Hal tersebut guna mengembangkan kemampuan mahasiswa, agar mahasiswa yang lulus telah memiliki bekal yang cukup dan siap untuk memasuki dunia kerja.

\section{DAFTAR PUSTAKA}

Abidin dan Daud (2012). Personality traits: business versustechnical graduates. communications of the IBIMA. 2, 1-15.

Ames, C. dan Archer, J. (1988). Achievement goals in the classroom: students'learning strategies and motivation processes. Journal of educational psychology, 80, 260-267.

Archer dan Davison (2008). Graduate employability. Council for industry and higher education. 
Ashton, M. C., \& Lee, K. (2007). Empirical, theoretical, and practical advantages of the hexaco model of personality structure. Personality and social psychology review. 150-166.

Ashton, M. C \& Lee, K (2009) The HEXACO-60: a short measure of the major dimensions of personality. Journal of personality assessment. 91(4), 340-45.

Brady, R. P. (2009). Work readiness inventory administrastartor's guide. $\begin{array}{llll}\text { Diunduh tanggal } & 3 & \text { januari } & 2016\end{array}$ darihttps://www.careerkids.com/uploads/ckdownloads/workreadinessi nventory.pdf

Button, et.al. (1996). Goal orientation in organizational research:a conceptual and empirical foundation. Organizational behavior and human decision processes, 67, 26-48.

Caballero, C., \& Walker, A. (2010). Work readiness in graduate recruitment and selection: A review of current assessment methods. Journal of Teaching and Learning for Graduate Employability, 1(1), 13-25.

Caballero, C., Walker, A., \& Fuller-Tyszkiewicz, M. (2011). The work readiness scale (wrs): developing a measure to assess workreadiness in college graduates.Journal of teaching and learning for graduate employability, 2(2), 4154.

Carol, A. (2014). Factors influencing work readiness of graduates: an exploratory study. Stellenbosch University.

Cohen (2009). School climate: research, policy,practice, and teacher education. Teachers college record, 111, 180-213.

Devine, J. \& Cohen, J. (2007). Making your school safe: Strategies to protect children and promote learning. New York: Teachers CollegePress.

Educational Testing Service (2012). Relationships between big five and academic and workforce outcomes. Diunduh tanggal 3 oktober 2016 darihttps://www.ets.org/s/workforce readiness/pdf/21334 big 5.pdf

Ferns, S. (2012). Graduate employability: Teaching staff, employer and graduate perceptions. Australian Collaborative Education Network (ACEN Inc.).

Friedman, N. U., \& Schustack, N. W. (2006). Kepribadian: teori klasik dan riset modern (3nd ed.). (D. I. Fransiska, H. Maria, \& P. P. Andreas, Trans.) Jakarta: Erlangga.

Haahr, J.H., Nielsen, T.K., Hansen, M.E., \& Jakobsen, S.T. (2005). Explaining student performance. Evidence from the internationalPISA, TIMSS and PIRLS surveys. Danish Technological Institute,Denkmark.

Hope Clark. (2013). Work readiness standards and benchmarks. America: act,inc.

J. Ellershaw, et.al. (2015). Openness to experience and extraversion aspredictors of nursing work performance: a facet-level analysis. Journal of nursing management.

Jackson, D. (2013). $\quad$ The contribution of work-integrated learning to undergraduate employability skill outcomes. Asia-pacific journal of cooperative education, 14(2), 99-115.

John, O. P., Robins, R. W., \& Pervin, L. A. (2008). Handbook of personality : theory and research. New York: The Guilford Press. 
Karen L. Harvey (2012). Job readiness training curriculum. Diunduh pada tanggal 32 januari 2017 dari http://www.baltoworkforce.com/documents/ri east balt jrt curriculum . $\mathrm{pdf}$

Kellermann, P dan Sagmeister, G. (2010). Higher education and graduateemployment in austria.European journal of education, 3(2), 140-146.

Ketut, Sukardi Dewa (2002). Pengantar pelaksanaan program bimbingan dan konseling di sekolah. Jakarta: rineka cipta.

Klein, et.al. (2012).Relationships between bullying, school climate, and student riskbehaviors. American psychological association, 27(3), 154-169.

Landrum, et.al. (2010). Alumni perceptions of workforce readiness. Teaching of psychology, 37(2), 97-106.

Lestari, W.T. (2013). Empathy. Jurnal Fakultas Psikologi, 3(2).

Marshall, M. L. (2004). Examining school climate: defining factors and educational influences. Georgia state university center for school safety, school climate and classroom management.

Mason, G., et.al. (2006). Employability skills initiatives inhigher education: what effects do they have on graduate labour marketoutcomes. National Institute Of Economic And Social Research. Jurnalditerima dari http://www.niesr.ac.uk/pubs/DPS/dp280.pdf

Mitchell, et.al. (2010). Student and teacher perceptionsof school climate: a multilevelexploration of patterns of discrepancy. Journal of school health, 80(6), 271-280.

Paul dan Philip (2014). Which personality attributes are most important in the workplace?. Perspectives on psychological science, $9,538$.

Pintrich, P.R. \& Shunk, D.H., Meece, J.L. (2002). Motivation in education theory, research, and applocations. The university of north carolina at chapell hill: pearson merrill pretince hall.

Pintrich, P.R. \& Shunk, D.H. (2008). Motivation in education theory, research, and application. Englewood cliffs, nj: prentice hall.

Pool, L. D. dan Sewell, P. (2007). The key to employability: developing a practical model of graduate employability. Journal education and training, 49(4), 277-289.

Rathus, S. A. (2010). Psychology: concept and connections (10nd ed.). United States: Wadsworth Cengage Learning.

Rich A. Radcliffe \& Beth (2013). Strategies to prepare middle school and high school students for college and career readiness. The Clearing House: $A$ journal of Education Strategies, 86(4), 136-141.

Ruhimat. (2011). Mobilitas tenaga kerja indonesia dalam era globalisasi.Jurnal pendidikan geografi, 6(1).

Si Man Lam \& Ching-I Teng (2008). Time pressure, nurse conscientiousness, and patient safety.

Solberg, Good, dan Nord (1995). Career decision-making and career search activities: Relative effects of career search self-efficacy and human agency. Journal of Counseling Psychology, 42(4), 448-455. 
Staci, C. (2007). The influence of goal orientation on trainee learing strategies and outcomes of a work readiness program.

Suroso. (2015). Masyarakat Ekonomi ASEAN (MEA) dan Perekonomian Indonesia. Diunduh pada tanggal 8 januari 2016 http://www.bppk.kemenkeu.go.id/publikasi/artikel/150-artikelkeuangan-umum/20545-masyarakat-ekonomi-ASEAN-mea-danperekonomian-indonesia

Thapa, et.al. (2012). School Climate Research Summary. Diunduh pada tanggal 3 april 2016

https://www.schoolclimate.org/climate/documents/policy/sc-briefv3.pdf

Uline, C. \& Tschannen-Moran, M. (2008). The walls speak: The interplayof quality facilities, school climate, and student achievement.Journal of Educational Administration, 46(1), 55-73.

Vande Walle, et.al. (1998). The influence of goal orientation and self-regulation tactics on sales performance: a longitudinal field test.

Wagner, J. O. (2006). Work readiness skill. The Ohio State University.

Wall, B. (2007). Coaching for emotional intelligence. New York: Amacom.

Wilda, R. (2014). 8 profesi ini bebas berkeliaran di asean. Diunduh pada tanggal 8 januari 2016 http://careernews.id/youknow/view/3000-8-profesi-inibebas-berkeliaran-di-asean

Yousef\& El-Houfey (2014). Compatibility of personality traits with the profession for faculty of nursing students at assiut university. British journal of education, 2(3), 44-56.s

Yuda P. (2015).Kesiapan pekerja Indonesia sambutmea dan outlook 2015. Diunduh pada tanggal 102016 http://topcareermagazine.com/placeholders/pdf/vol39.pdf 